\title{
Neuroprotective Effects of Chronic Fenofibrate Treatment via Modulating the Immunoreactivity of Cleaved Caspase-3 in Stroke Induced by Transient Middle Cerebral Artery Occlusion Rat Model
}

\author{
Ozge ALTINTAS ${ }^{1}$, Mehmet Ozgen ALTINTAS ${ }^{2}$, Mehmet Serif AYDIN³ ${ }^{3}$, Oguz BARAN ${ }^{4}$, Veysel ANTAR ${ }^{4}$, \\ Mukaddes ESREFOGLU ${ }^{3}$, Talip ASIL ${ }^{5}$ \\ ${ }^{1}$ Bor State Hospital, Neurology Clinic, Nigde, Turkey \\ ${ }^{2}$ Fatih University, Faculty of Engineering, Department of Genetics and Bioengineering, Istanbul, Turkey \\ ${ }^{3}$ Bezmialem Vakif University, Department of Histology and Embriology, Istanbul, Turkey \\ ${ }^{4}$ Istanbul Research and Training Hospital, Neurosurgery Clinic, Istanbul, Turkey \\ ${ }^{5}$ Bezmialem Vakif University, Department of Neurology, Istanbul, Turkey
}

\section{ABSTRACT}

AIM: Current stroke therapies include lipid-lowering drugs, which reduce inflammation and serve to stabilize the atherosclerotic plaque to demonstrate better outcome and neuroprotection. Peroxisome proliferator activated receptors (PPAR) a regulates lipid homeostasis and is a target of fibrates, which have a neuroprotective function by various mechanisms. In this study, we aimed to evaluate the role of the PPARa agonist, fenofibrate, in the modulation of cleaved caspase-3 immunoreactivity and at the final infarct volume in an experimental ischemia/reperfusion rat model by induced transient proximal middle cerebral artery occlusion.

MATERIAL and METHODS: A total of 65 male Sprague Dawley rats were allocated into 4 groups; sham $(n=5)$, experiment 1 ( $n=20)$, experiment $2(n=20)$, experiment $3(n=20)$. All experiment groups were divided to 3 subgroups in order to evaluate the final infarct volume at $24^{\text {th }}$ hour $(n=5)$ and the immunoreactivity of cleaved caspase -3 at different time periods [at first hour $(n=5)$, at $6^{\text {th }}$ hour $(n=5)$, at $24^{\text {th }}$ hour $\left.(n=5)\right]$ after transient middle cerebral artery occlusion (MCAo). At the study, the experiment groups (Experiment 1 and Experiment 2) were received the fenofibrate-diet during 14 days before ischemia procedure. All animals were sacrificed at $24^{\text {th }}$ hours after MCAo. Infarction volumes were calculated from 2,3,5,triphenyltetrozolium chloride (TTC)- stained brain sections.

RESULTS: We found that fenofibrate-therapy reduced significantly more body weight than the other experiment groups $(p<0.05)$. At the time intervals, a decrease of immunoreactivity of cleaved caspase- 3 was significantly observed with fenofibrate therapy after MCAo $(p<0.05)$. Chronic fenofibrate treatment before cerebral ischemia significantly reduced the infarction size after MCAo compared with the other groups (respectively; $p=0.011$ and $p<0.000$ ).

CONCLUSION: Fenofibrate treatment has neuroprotective effects on middle cerebral artery infarcts.

KEYWORDS: Neuroprotection, Fenofibrate, Stroke, Caspase-3 


\section{INTRODUCTION}

S troke is the second leading cause of mortality and the third leading cause of morbidity worldwide (16). Current therapies for ischemic stroke include primary and secondary preventive therapies. Particularly, these new stroke prevention therapies may help to reduce inflammation, serve to stabilize the atherosclerotic plaque, or act by other protective mechanisms (10). Lipid lowering drugs also exert a preventive neuroprotection in strokes that occur despite the preventive measures, as demonstrated by a better outcome for patients receiving lipid-lowering drugs prior to stroke occurrence (5). The basic mechanisms involved in this preventive neuroprotection have been identified in experimental models. For fibrates, the mechanism involves the nuclear receptor, peroxisome proliferator activated receptors alpha (PPARa) (7).

Peroxisome proliferator activated receptors (PPARs), members of the nuclear receptor superfamily, are ligand-activated transcription factors with diverse actions including regulation of adipocyte differentiation and lipid metabolism (22). PPARa regulates lipid homeostasis and is a target of fibrates, which are used clinically for the treatment of hypertriglyceridemia (20). The PPARa agonist fenofibrate has a neuroprotective function by inhibiting the central mediator, Tumor necrosis factor (TNF), of neuroinflammation and apoptosis due to antagonize activities of transcription factors such as NF- $\mathrm{k} \beta$ $(2,3)$. TNF is cytokine, which is the major extrinsic mediator of apoptosis (8).

Apoptotic cell death is a highly regulated process that in many cases requires activation of caspases. Caspase-3, an executioner caspase, plays a central role in apoptosis following transient brain ischemia (14). Studies have suggested that caspase-3 activation does not mean the cells are dead. Cleavage of caspase- 3 is therefore a well-established marker for apoptotic cell death (18).

In this study, we aimed to evaluate the role of the PPARa agonist, fenofibrate, in the modulation of cleaved caspase-3 immunoreactivity and the final infarct volume in an experimental ischemia/reperfusion rat model by induced transient proximal middle cerebral artery occlusion.

\section{MATERIAL and METHODS}

\section{Animals}

All animals were obtained from the Experimental Animal Research Laboratory at Bezmialem Vakif University, Istanbul, Turkey. Animals were allowed free access to food and water at controlled room temperature $\left(22-25^{\circ} \mathrm{C}\right)$ under a 12:12$\mathrm{h}$ day/night cycle for the duration of the study. During the surgical procedures, body temperature was monitored using a Nimomed infrared thermometer. All procedures were approved by the Animal Care and Use Committee at Bezmialem Vakif University and performed in accordance with institutional guidelines.

\section{Middle Cerebral Artery Occlusion (MCAo)}

The most common stroke model, due to its relevance to human stroke, is focal MCAo (11). In the present study, we induced transient proximal MCAo to cause ischemia-reperfusion injury to assess the neuroprotective effect of prophylactic chronic treatment with fenofibrate. Animals underwent a 1-hour MCAo, followed by reperfusion for 24-hours.

Moreover, studies have found that cleaved caspase-3 activity increased gradually within 24 hours in the infarct core after transient MCAo; but the activity was overall lower in the nonperfused core after permanent occlusion, suggesting that caspase- 3 activity depends on reperfusion by the fact that free radicals generated during reperfusion $(6,14,18)$. So at our study, we demonstrated the ischemia-reperfusion MCAo rat model to observe the cleaved caspase- 3 association with ischemic infarct volume.

Focal cerebral ischemia was induced using an endovascular middle cerebral arterial occlusion technique, as described previously (11). Briefly, animals were anesthetized with ketamine $(4 \mathrm{mg} / 100 \mathrm{~g})$ and xylazine $(1.5 \mathrm{mg} / 100 \mathrm{~g})$ by intramuscular injection and placed on an operation plate in the supine position. Their heads and limbs were fixed. After shaving and sterilization, a cervical median incision (3-4 $\mathrm{cm}$ long) was made. Precervical fascia and muscle were isolated with forceps, and fascia and muscle on the inside of the sternocleidomastoid were dissociated. Arterial pulses were visible. Tissues surrounding the artery were carefully dissociated, without injury to the vagus nerve. The left common carotid artery and the left external carotid artery were exposed through a midline neck incision. The proximal part of the left common carotid artery and root of the external carotid artery were ligated. The pterygopalatine artery was dissociated upwards along the internal carotid artery, and ligated. A 4.0 Medium B MCAO monofilament nylon suture (Doccol), whose tip had been coated with silicone, was then inserted through an arteriotomy of the left common carotid artery and gently advanced into the internal carotid artery to a point $\sim 15-16$ $\mathrm{mm}$ distal to the carotid bifurcation. We used Gerriets and colleagues' method (9) to assess the success of the MCA occlusion. Therefore, the method is not useful to document that the MCA occlusions are uniform. Mild resistance to this advancement indicated that the suture had entered the anterior cerebral artery, thus occluding the origins of the MCA. The left common carotid artery was loosely ligated just distal to the arteriotomy, after which the neck wound was closed. After 60 minutes, the suture was carefully removed; its tip was blocked by a microclamp placed on left common carotid artery to allow reperfusion. The sham operation consisted of the same manipulation but without introduction of the monofilament.

\section{Study Design}

Sixty-five male Sprague-Dawley rats $(450-500 \mathrm{~g} ; 10-12$ months old) were allocated to four groups; sham operated group $(n=5)$, experiment-1 group $(n=20)$, experiment -2 group $(n=20)$, and experiment-3 group $(n=20)$. Transient proximal MCAo was induced in all experiment groups after treated drugs during 14 days. All experiment groups were divided to 3 subgroups in order to evaluate the final infarct volume at $24^{\text {th }}$ hour $(n=5)$ and the immunoreactivity of cleaved caspase -3 at different time period [at first hour $(n=5)$, at $6^{\text {th }}$ hour $(n=5)$, at 
$24^{\text {th }}$ hour $\left.(n=5)\right]$ after MCAo. All animals were sacrificed at $24^{\text {th }}$ hours after MCAo. Also all animals were weighed everyday during the study period. Study design was showed at Table I.

\section{Drug Administration}

The experiment groups (Experiment-1 and Experiment-2) received the fenofibrate diet for 14 days before ischemia procedure, because mechanisms of fibrate-induced preventive neuroprotection involve genomic regulation by nuclear receptor PPARa pathways.

A-Sham operated Group ( $n=5)$ : These animals were fed a standard diet. This group did not undergo any surgical procedure.
B-Experiment-1 Group ( $n=20)$ : These animals were treated for 14 days with vehicle (10\% (v/v) Dimethylsulfoxide (DMSO) $2 \mathrm{ml} /$ day) by oral administration through a feeding needle. Dimethylsulfoxide (DMSO) is a common vehicle used for many drugs used in neuroprotective experiments. DMSO has many biological effects, including anti-inflammatory, antioxidant, and local anesthetic effects and recently the researches investigated its neuroprotective effects (23). So we decided to allocate the vehicle group to the study due to determine the neuroprotective effect of fenofibrate. This group was called DMSO+MCAo.

C-Experiment-2 Group ( $n=20)$ : These animals were treated for 14 days with Fenofibrate (FB) $(200 \mathrm{mg} / \mathrm{kg}$ was dissolved in $10 \%(\mathrm{v} / \mathrm{v})$ Dimetil Sulfoxide (DMSO) $2 \mathrm{ml} /$ day) by oral

Table I: The Study Groups, Procedures and Number of Rats in Each Group

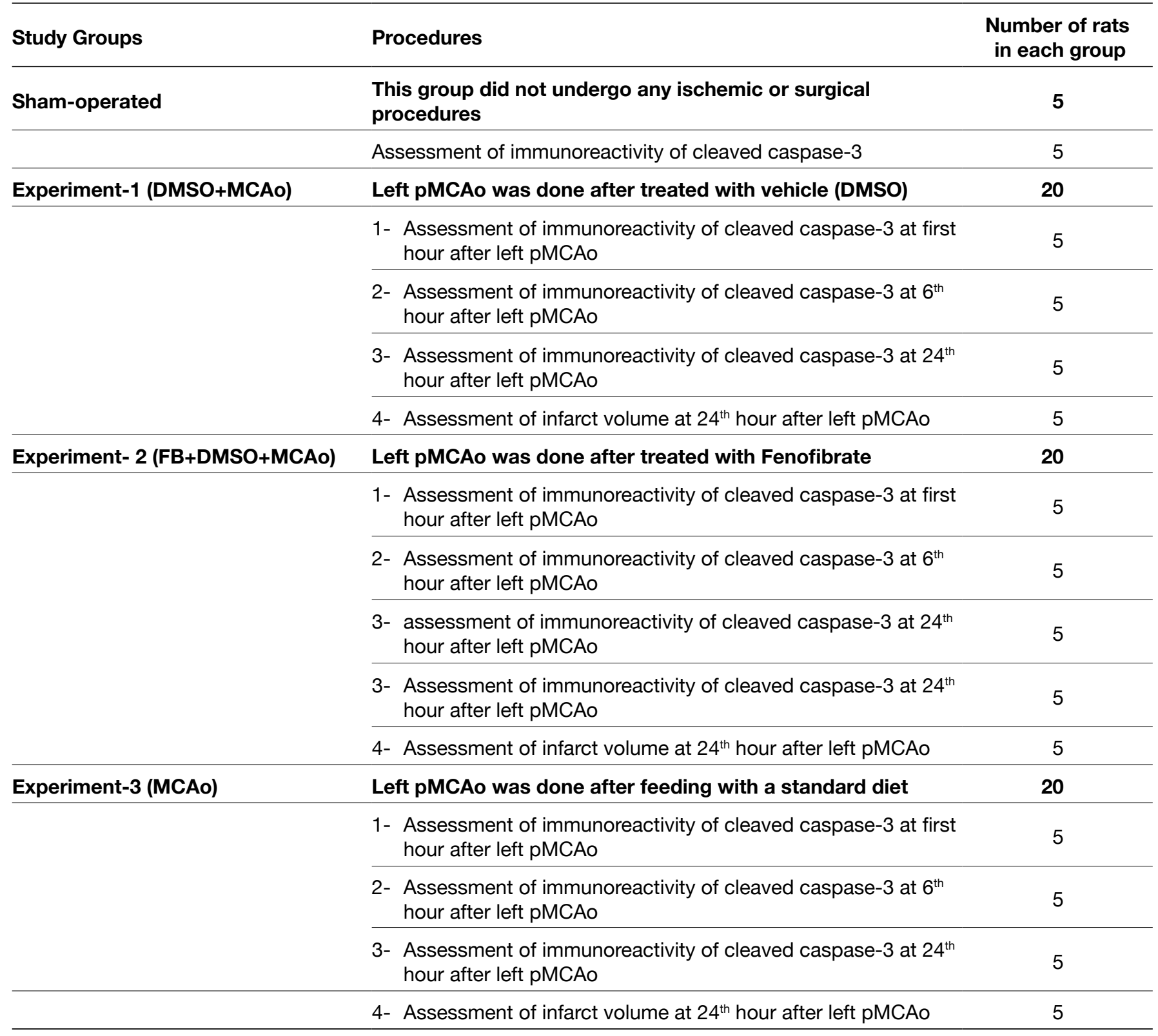


administration through a feeding needle. This group was called FB+DMSO+MCAo.

D-Experiment-3 Group ( $n=20)$ : These animals were fed a standard diet during 14 days. This group was called MCAo.

\section{Assessment of Infarct Volume}

Infarct volumes were calculated using 2,3,5,triphenyltetrozolium chloride (TTC)- stained brain sections, as described previously (1). Briefly, after the animals were sacrificed, the brains were removed immediately and cut into $2-\mathrm{mm}$ sections. Samples were then incubated for $30 \mathrm{~min}$ in a $2 \%$ solution of TTC at $37^{\circ} \mathrm{C}$ and fixed by immersion in $10 \%$ buffered formalin solution. Five brain sections per animal were stained with $\Pi \mathrm{TC}$ and then photographed. Cerebral infarct volumes were calculated using the image analysis program of Adobe Photoshop CS5 extended (version 12.1).

\section{Assessment of Immunoreactivity of Cleaved Caspase-3:}

$10 \mu \mathrm{m}$ coronal sections of brain were cut with cryostat (CM1520, Leica Bio systems Nussloch $\mathrm{GmbH}$ ) and were fixed with $4 \%$ paraformaldehyde for $1 \mathrm{~h}$. Caspase 3 activity was determined in coronal cryosections of ischemic hemispheres using the rabbit polyclonal anti-active + pro Caspase 3 primary antibody (1:100, Cat. \# ab13847, Abcam, UK), which had been incubated for $18 \mathrm{~h}$ at $4^{\circ} \mathrm{C}$ followed by repeated washing steps. Thereafter, goat anti-rabbit alexa fluor 488 secondary antibody (1:400, Cat. \# A-11034, Thermo Fisher Scientific) was used for $1 \mathrm{~h}$ at room temperature. Sections were counterstained with propidium iodide (500nM, Cat. \# P3566, Thermo Fisher Scientific). Stainings were analyzed by quantifying caspase-3 positive cells in twelve ROI under a confocal microscope (LSM 780, Carl Zeiss, Jena, Germany).

\section{Statistical Analysis}

Continuous measurements are expressed as mean and standard deviation for each group. ANOVA and Kruskal-Wallis tests were used to assess the effectiveness of intervention and group differences in infarct size and weights of rats, along with levels of caspase-3. Dunn's test (non-parametric) and Tukey (parametric) test was used for multiple comparisons after Kruskal-Wallis and ANOVA, respectively.

$\mathrm{P}$-values $<0.05$ were considered statistically significant.

\section{RESULTS}

\section{Mortality}

None of animals died during the study period.

\section{Effect of Fenofibrate on Body Weight}

Since fenofibrate seems to act as a weight-stabilizer on genetic/diet-induced obesity mainly through its effect on liver metabolism (15), we decided to observe its metabolic effect on the body weight of the rats every day.

Before MCAo, at the $7^{\text {th }}$ day and $14^{\text {th }}$ day, the study groups that were treated with DMSO +FB or only DMSO lost weights significantly compared to other groups that were fed a standard diet (at $7^{\text {th }}$ day FB+DMSO+MCAo vs. MCAo $p=0.016$; DMSO+MCAo vs. MCAo $p=0.010$ and at $14^{\text {th }}$ day $\mathrm{FB}+\mathrm{DMSO}+\mathrm{MCAo}$ vs. MCAo $\mathrm{p}=0.005$; DMSO+MCAo vs. MCAo $p=0.003$, respectively). Moreover, we investigated that fenofibrate-therapy significantly reduced body weight rather than vehicle-therapy group (at $7^{\text {th }}$ day and at $14^{\text {th }}$ day, $\mathrm{FB}+\mathrm{DMSO}+\mathrm{MCAo}$ vs. DMSO+MCAo $\mathrm{p}<0.000$ ). The bodyweights of the study groups were showed at Figure 1.

These results suggest that changes in body weight were associated with the therapeutic potential of Fenofibrate.

\section{Time Course of Cleaved Caspase-3 Immunoreactivity in Ischemic Brain}

The immunoreactivity of positive caspase- 3 cells was detected at the first hour, $6^{\text {th }}$ hour and $24^{\text {th }}$ hour after left MCAo. Among the study groups, the caspase-3 cleavage activation was not significantly different at the first hour after MCAo ( $p>0.99$ among groups) (Figure 2). At the $6^{\text {th }}$ hour and at $24^{\text {th }}$ hour after MCAo, Caspase -3 cleavage activity was significantly lower in the $\mathrm{FB}+\mathrm{DMSO}+\mathrm{MCA}$ group relative to the $\mathrm{DMSO}+\mathrm{MCA}$ and MCAo groups $\left(p=0.005\right.$ and $p=0.001$ at the $6^{\text {th }}$ hour; $p=0.003$ and $p=0.004$ at the $24^{\text {th }}$ hour after MCAo, respectively), (Figure 2). Therefore; at these intervals, a significant decrease in the immunoreactivity of cleaved caspase-3 was not observed with DMSO (vehicle) therapy after MCAo ( $p>0.99)$ (Figure 2). The temporospatial distribution of cells with cleaved caspase-3 after transient MCAo is shown in Figure 3.

Collectively, these data demonstrate that chronic fenofibrate treatment as a PPAR activator could protects the neurons against ischemia by modulating the early phase of apoptosis. Moreover, we also suggest that this neuroprotective effect is independent of its vehicle.

\section{Fenofibrate pre-treatment reduces the total infarct volume}

TTC-derived infarct volumes $\left(\mathrm{mm}^{3}\right)$ in the $\mathrm{FB}+\mathrm{DMSO}+\mathrm{MCAO}$, DMSO+MCAo and MCAo groups are shown in Figure 4. Chronic fenofibrate treatment before cerebral ischemia significantly reduced infarction size after MCAO compared with the other groups (respectively; $p=0.011$ and $p<0.000$ ). $A$ TTC-stained brain section is shown in Figure $5 \mathrm{~A}-\mathrm{C}$.

\section{DISCUSSION}

In the present study, we have demonstrated (in the rat) that a 14-day pre-ischemic administration of fenofibrate significantly decreases the cerebral infract volume. This neuroprotective effect was associated with partial prevention of apoptosis after ischemia-reperfusion injury.

The mechanism by which PPARa activation by fenofibrate exerts cerebrovascular protective effects remains unknown. The neuroprotective effect of fenofibrate is independent of the well-documented lipid lowering effects of PPARa activators reported in various studies. At the Cochrane database, the researches have recently suggested that the fibrate class can be effective in the secondary prevention of composite outcome of non-fatal stroke, non-fatal MI, and vascular death (25). The normalization of the hypertriglyceridemia and hyperglycaemia by fenofibrate might contribute to its neuroprotective effect by 

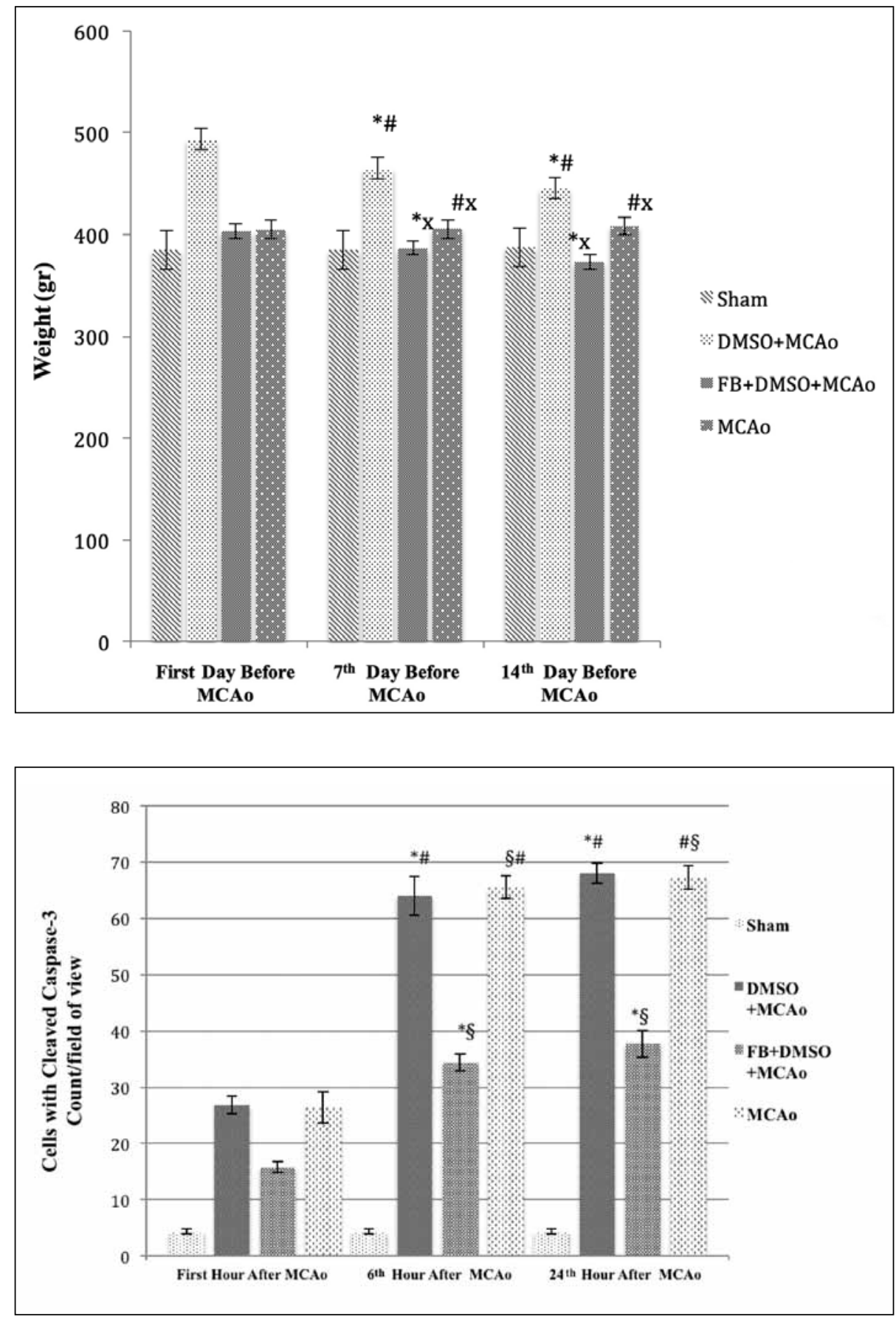

Figure 1: Rats were weighted during 14-day before MCAo. The data are expressed as mean \pm standard error ( ${ }^{*} \# p<0.05$, Kruskal -Wallis test, post hoc Dunn's Test).

[For each group respectively; First day, Sham $=385 \pm 19.20 \mathrm{gr} ; \mathrm{DMSO}+\mathrm{MCAo}=$ $493.45 \pm 10.71 \mathrm{gr} ; \mathrm{FB}+\mathrm{DMSO}+\mathrm{MCAo}=$ $403.45 \pm 7.09 \mathrm{gr} ; \mathrm{MCAO}=404.70 \pm 9.05 \mathrm{gr}$ $7^{\text {th }}$ day, Sham $=385 \pm 19.20 \mathrm{gr}$; $\mathrm{DMSO}+\mathrm{MCAO}=465 \pm 8.93 \mathrm{gr}$; $\mathrm{FB}+\mathrm{DMSO}+\mathrm{MCAo}=386.90 \pm 5.72 \mathrm{gr}$ $M C A o=405.20 \pm 9.40 \mathrm{gr} 14^{\text {th }}$ day, Sham $=387.80 \pm 19.66 \mathrm{gr}$; $\mathrm{DMSO}+\mathrm{MCAO}=445.65 \pm 5.82 \mathrm{gr}$; $\mathrm{FB}+\mathrm{DMSO}+\mathrm{MCAO}=373.30 \pm 5.49 \mathrm{gr}$ $\mathrm{MCAO}=408.40 \pm 8.98 \mathrm{gr}]$.

Figure 2: Quantitative analysis of cells with cleaved caspase-3 (count/ field of view) at first, at $6^{\text {th }}$ and $24^{\text {th }}$ after MCAo were established under a confocal microscope (LSM 780, Carl Zeiss, Jena, Germany). The data are expressed as mean \pm standard error $(\$ \# p<0.05$, Kruskal -Wallis test, post hoc Dunn's test).

For each group respectively; Sham = $\mathrm{FB}+\mathrm{DMSO}+\mathrm{MCAO}=14.26 \pm 4.05 \mathrm{~mm}^{3}$; $\mathrm{DMSO}+\mathrm{MCAo}=34.58 \pm 2.07 \mathrm{~mm}^{3} ; \mathrm{MCAo}=$ $60.80 \pm 8.71 \mathrm{~mm}^{3}$

$(p>0.99)$

$\left({ }^{*}, p=0.005 ; x, p=0.001 ; \#, p>0.99\right)$

$\left.{ }^{*}, p=0.003 ; x, p=0.004 ; \#, p>0.99\right)$. decreasing anti-atherotrombogenic factors (12). However, in normoglycemic or normolipidemic experimental rat ischemic models, studies also showed the neuroprotective effect of fenofibrate (4). We therefore evaluated the molecular target activated by fenofibrate to prevent the brain after ischemia.

During acute neuronal damage, necrosis is the most prominent cell death phenotype in the infarct core, whereas apoptosis predominates at the penumbra. Previous data showed that the post-ischemic activation of NF-k $\beta$ dependent genes has a key modulation on proinflammatory and proapoptotic mediators. Activation of PPARa by binding of fenofibrate leads to inhibition of NF-K $\beta$ and concurrently the inhibition of apoptosis $(21,24)$. Caspase-3, which is considered the prototype of executioner caspases and is the most plentiful caspase in the brain dependent apoptosis leads to potentially important implications for developing therapeutic strategies especially for stroke (8). At our study, we evaluated timedependent changes in cleaved caspase-3 during reperfusion after transient MCAo. Cleaved caspase-3 did not appear in the normal brain; but the immunoreactivity changed over time when measured in three different time points after MCAo. The 


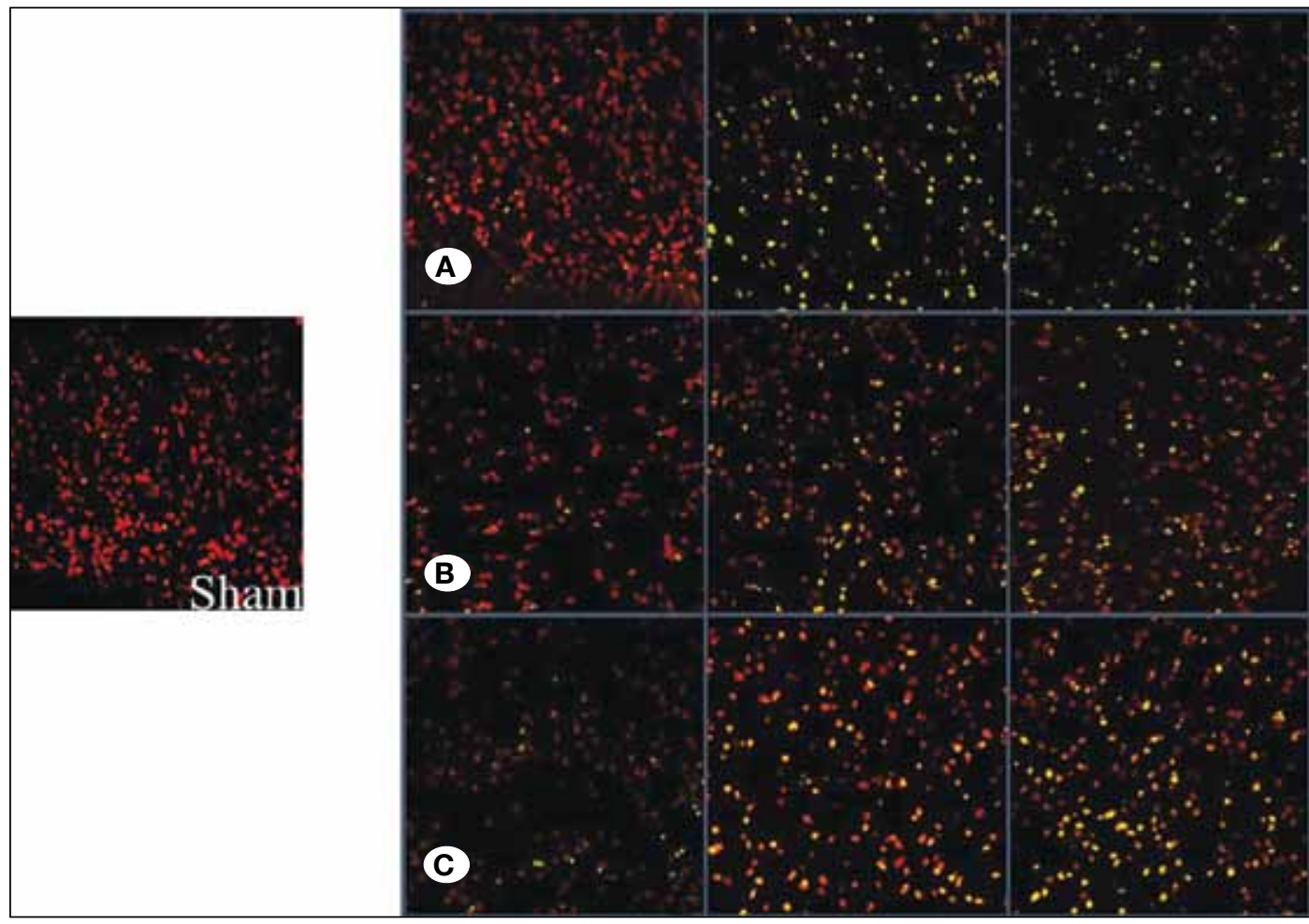

Figure 3: Pre-ischemic Fenofibrate administration inhibits the expression of cleaved caspase- 3 at first hour, at $6^{\text {th }}$ hour and $24^{\text {th }}$ hour after transient MCAo. Stainings were analyzed by quantifying caspase-3 positive cells (green) in brain tissue specimens in twelve ROI under a confocal microscope (LSM 780, Carl Zeiss, Jena, Germany). A) DMSO+MCAo group at first, at $6^{\text {th }}$ hour and $24^{\text {th }}$ hour after transient MCAo. B) $\mathrm{FB}+\mathrm{DMSO}+\mathrm{MCAo}$ group at first hour, at $6^{\text {th }}$ hour and $24^{\text {th }}$ hour after transient MCAo. C) MCAo group at first hour, at $6^{\text {th }}$ hour and $24^{\text {th }}$ hour after transient MCAo.

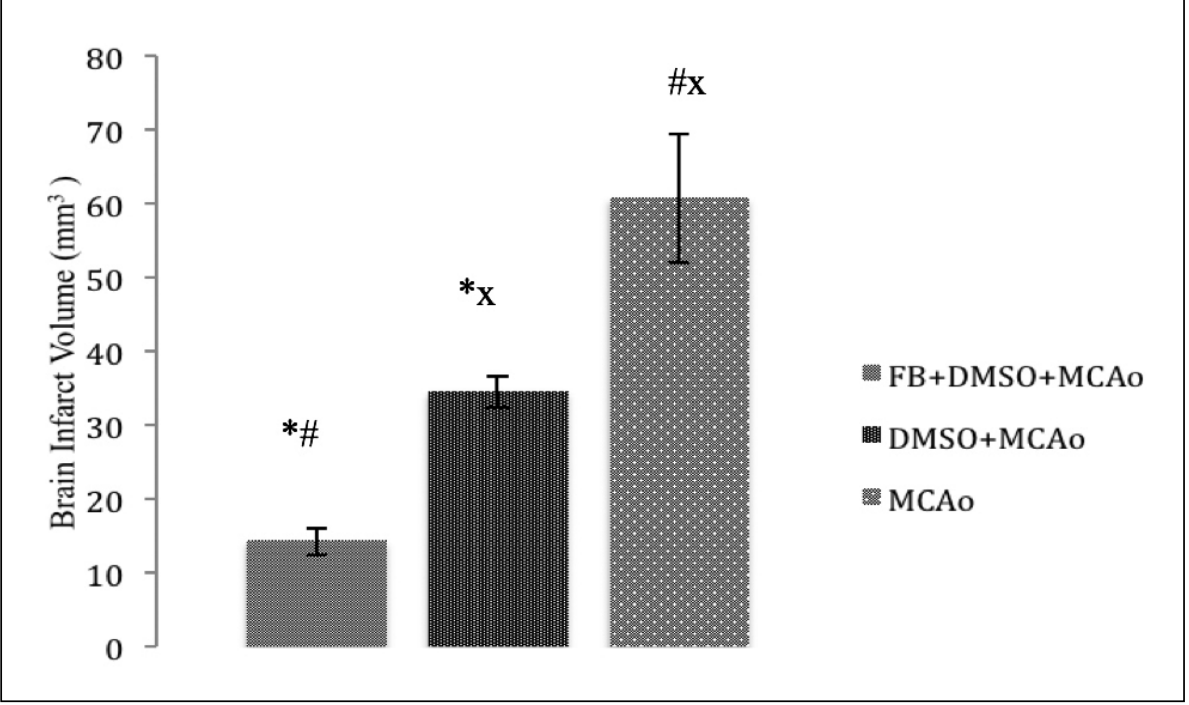

Figure 4: Brain infarct volume $\left(\mathrm{mm}^{3}\right)$ at $24^{\text {th }}$ hour after MCAo. The data are expressed as mean \pm standard error (" $x \# p<0.05$, Kruskal -Wallis test). For each group respectively; $\mathrm{FB}+\mathrm{DMSO}+\mathrm{MCAO}=14.26 \pm 4.05 \mathrm{~mm}^{3}$; $\mathrm{DMSO}+\mathrm{MCAO}=34.58 \pm 2.07 \mathrm{~mm}^{3}$; $\mathrm{MCAO}=60.80 \pm 8.71 \mathrm{~mm}^{3}$.

level immunoreactivity of cleaved caspase-3 was decreased significantly in the pre-ischemic fenofibrate treatment group.

Our findings are in good agreement with other studies having demonstrated the neuroprotective effect of modulating the nuclear PPARa receptors. In a recent study, the importance of the anti-inflammatory effect had already been suggested to prevent the decrease of vascular adhesion protein expression in the ischemic zone (19). Deplanque et al. showed that chronic treatment with fenofibrate increased major antioxidant enzymes including copper/zinc superoxide dismutase in the nonischemic mouse brain, which is likely to contribute to the neuroprotection in the brain after ischemia (4). Another study showed that pretreatment with fenofibrate improved the penumbral cerebral blood flow during MCAo (17). Recently, Losey et al. observed that a 14-day fenofibrate pre-treatment decreased reactant production, infarct volume, and neutrophil recruitment to the brain and liver, which is a hallmark of the acute phase response (14).

\section{CONCLUSION}

Pre-ischemic administration of fenofibrate has a preventive protective effect against brain ischemia by decreasing infarct volume related to possible genomic modulation in 


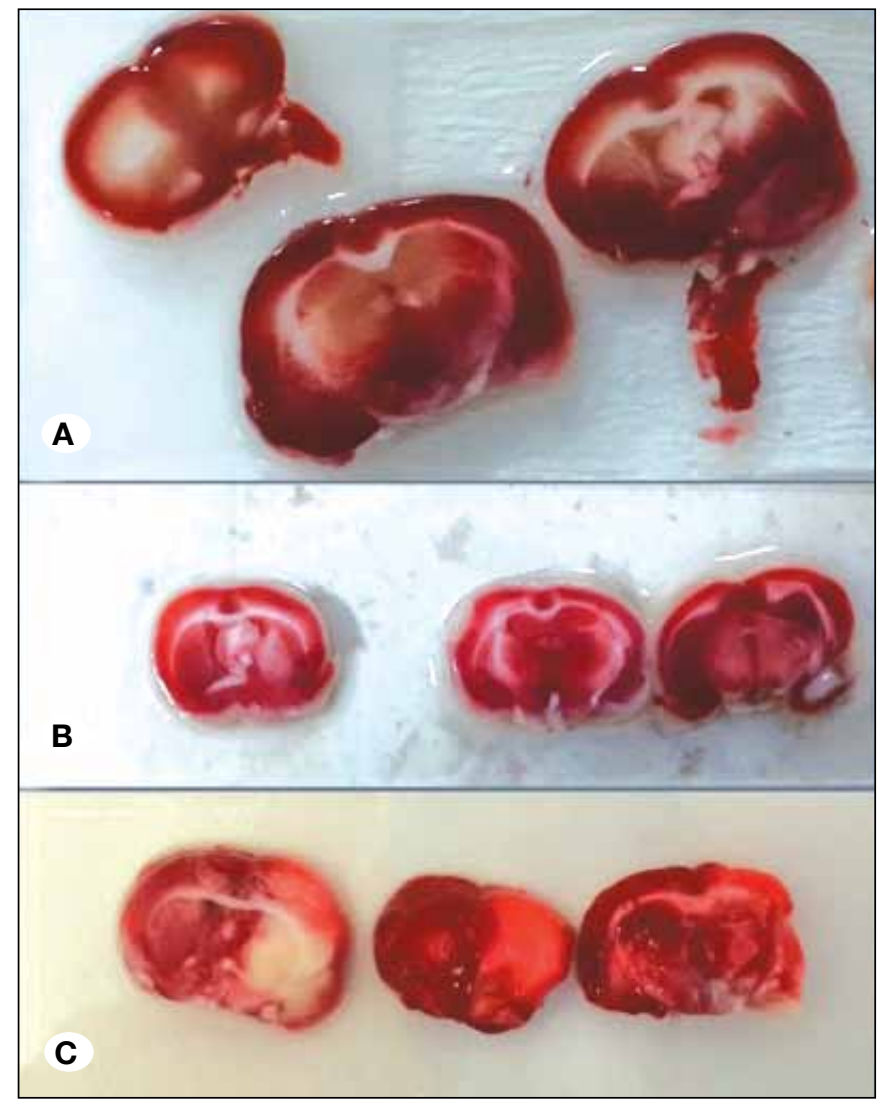

Figure 5: Brain sections were stained with TTC, demonstrating ischemic injury. Ischemic infarcts (white areas indicating brain damage) are substantially smaller in $\mathrm{FB}+\mathrm{DMSO}+\mathrm{MCA}$ group.

A) DMSO+MCAo group, B) $\mathrm{FB}+\mathrm{DMSO}+\mathrm{MCAo}$ group, C) MCAo group 24 hours after transient MCAo.

the apoptosis pathway. Moreover, further information on the ability to prevent injury by inhibiting signaling cascades upstream of caspase-3 activation should reveal the functional role of apoptosis inhibition for treatment of stroke.

\section{- REFERENCES}

1. Bederson JB, Pitts LH, Germano SM, Nishimura MC, Davis $\mathrm{RL}$, Bartkowski HM: Evaluation of 2,3,5-triphenyltetrazolium chloride as a stain for detection and quantification of experimental cerebral infarction in rats. Stroke 17: 1304-1308, 1986

2. Cunard R, Ricote M, Di Campli D, Archer DC, Kahn DA, Glass CK, Kelly CJ: Regulation of cytokine expression by ligands of peroxisome proliferator activated receptors. J Immunol 168(6): 2795-2802, 2002

3. Delerive P, De Bosscher K, Besnard S, Vanden Berghe W, Peters JM, Gonzalez FJ, Fruchart JC, Tedgui A, Haegeman G, Staels B: Peroxisome proliferator-activated receptor alpha negatively regulates the vascular inflammatory gene response by negative cross-talk with transcription factors NF-kappaB and AP-1. J Biol Chem 274(45): 32048-32054, 1999
4. Deplanque D, Gelé P, Pétrault O, Six I, Furman C, Bouly M, Nion S, Dupuis B, Leys D, Fruchart JC, Cecchelli R, Staels B, Duriez P, Bordet R: Peroxisome proliferator-activated receptor-alpha activation as a mechanism of preventive neuroprotection induced by chronic fenofibrate treatment. J Neurosci 23(15): 6264-6271, 2003

5. Deplanque D, Masse I, Lefebvre C, Libersa C, Leys D, Bordet R: Prior TIA, lipid-lowering drug use, and physical activity decrease ischemic stroke severity. Neurology 67(8): 14031410, 2006

6. Derugin N, Wendland M, Muramatsu K, Roberts T, Gregory $G$, Ferriero D, Vexler Z: Evolution of brain injury after transient middle cerebral artery occlusion in neonatal rat. Stroke 31: 1752-1761, 2000

7. Endres M, Laufs U: Effects of statins on endothelium and signaling mechanisms. Stroke 35(11 Suppl 1):2708-2711, 2004

8. Galluzzi L, Morselli E, Kepp O, Kroemer G: Targeting postmitochondrial effectors of apoptosis for neuroprotection. Biochim Biophys Acta 1787(5): 402-413, 2009

9. Gerriets T, Stolz E, Walberer M, Muller C, Kluge A, Bachmann A, Fisher M, Kaps M, Bachmann G: Noninvasive quantification of brain edema and the space-occupying effect in rat stroke models using magnetic resonance imaging. Stroke 35(2): 566-571, 2004

10. Guo Q, Wang G, Namura S: Fenofibrate improves cerebral blood flow after middle cerebral artery occlusion in mice. $\mathrm{J}$ Cereb Blood Flow Metab 30(1): 70-78, 2010

11. Kernan WN, Ovbiagele B, Black HR, Bravata DM, Chimowitz MI, Ezekowitz MD, Fang MC, Fisher M, Furie KL, Heck DV, Johnston SC, Kasner SE, Kittner SJ, Mitchell PH, Rich MW, Richardson D, Schwamm LH, Wilson JA; American Heart Association Stroke Council, Council on Cardiovascular and Stroke Nursing, Council on Clinical Cardiology, and Council on Peripheral Vascular Disease: Guidelines for the prevention of stroke in patients with stroke and transient ischemic attack: A guideline for healthcare professionals from the American Heart Association/American Stroke Association. Stroke 45(7): 2160-2236, 2014

12. Koizumi J, Yoshida Y, Nakaqawa Y, Ooneda G: Experimental studies of ischemic brain edema: 1. A new experimental model of cerebral embolism in rats in which recirculation can be introduced in the ischemic area. Jpn J Stroke 8: 1-8, 1986

13. Liu ZM, Hu M, Chan P, Tomlinson B: Early investigational drugs targeting PPAR-a for the treatment of metabolic disease. Expert Opin Investig Drugs 24(5): 611-621, 2015

14. Losey P, Ladds E, Laprais M, Geuvel B, Burns L, Bordet R, Anthony DC: The role of PPAR activation during the systemic response to brain injury. J Neuroinflammation 12:99, 2015

15. Manabat C, Han BH, Wendland M, Derugin N, Fox CK, Choi J, Holtzman DM, Ferriero DM, Vexler ZS: Reperfusion differentially induces caspase- 3 activation in ischemic core and penumbra after stroke in immature brain. Stroke 34(1): 207-213, 2003 
16. Mancini FP, Lanni A, Sabatino L, Moreno M, Giannino A, Contaldo F, Colantuoni V, Goglia F: Fenofibrate prevents and reduces body weight gain and adiposity in diet-induced obese rats. FEBS Lett 491(1-2): 154-158, 2003

17. Meschia JF, Bushnell C, Boden-Albala B, Braun LT, Bravata $\mathrm{DM}$, Chaturvedi $\mathrm{S}$, Creager MA, Eckel $\mathrm{RH}$, Elkind MS, Fornage M, Goldstein LB, Greenberg SM, Horvath SE, ladecola C, Jauch EC, Moore WS, Wilson JA; American Heart Association Stroke Council; Council on Cardiovascular and Stroke Nursing; Council on Clinical Cardiology; Council on Functional Genomics and Translational Biology; Council on Hypertension: Guidelines for the Primary Prevention of Stroke: A statement for healthcare professionals from the American Heart Association/American Stroke Association. Stroke 42(2): 517-584, 2014

18. Namura S, Zhu J, Fink K, Endres M, Srinivasan A, Tomaselli KJ, Yuan J, Moskowitz MA: Activation and cleavage of caspase-3 in apoptosis induced by experimental cerebral ischemia. $J$ Neurosci 18(10): 3659-3668, 1998

19. Ouk T, Laprais M, Bastide M, Mostafa K, Gautier S, Bordet $\mathrm{R}$ : Withdrawal of fenofibrate treatment partially abrogates preventive neuroprotection in stroke via loss of vascular protection. Vascul Pharmacol 51(5-6): 323-330, 2009
20. Pawlak M, Lefebvre P, Staels B: Molecular mechanism of PPARa action and its impact on lipid metabolism, inflammation and fibrosis in non-alcoholic fatty liver disease. J Hepatol 62(3): 720 - 733, 2015

21. Robertson GS, Crocker SJ, Nicholson DW, Schulz JB: Neuroprotection by the inhibition of apoptosis. Brain Pathol 10(2):283-292, 2000

22. Schoonjans K, Staels B, Auwerx J: The peroxisome proliferator activated receptors (PPARS) and their effects on lipid metabolism and adipocyte differentiation. Biochim Biophys Acta 1302(2): 93-109, 1996

23. Shimizu S, Simon RP, Graham SH: Dimethylsulfoxide (DMSO) treatment reduces infarction volume after permanent focal cerebral ischemia in rats. Neurosci Lett 239(2-3):125-127, 1997

24. Stahel PF, Smith WR, Bruchis J, Rabb $\mathrm{CH}$ : Peroxisome proliferator-activated receptors: "key" regulators of neuroinflammation after traumatic brain injury. PPAR Res 2008: 538141, 2008

25. Wang D, Liu B, Tao W, Hao Z, Liu M: Fibrates for secondary prevention of cardiovascular disease and stroke. Cochrane Database Syst Rev 10: CD009580, 2015 